\title{
Factors Contributing to Red Blood Cells Crossmatch and Transfusion among Obstetrics Patients in a Single Tertiary Hospital
}

Ismail A $^{a}$, Abdul Karim F $F^{b}$, Iliassa II ${ }^{c}$, Noordin SS

${ }^{a}$ Transfusion Medicine Unit, Department of Pathology, Hospital Teluk Intan, Perak, Malaysia

${ }^{b}$ Department of Pathology, Hospital Ampang, Taman Pandan Mewah, Selangor, Malaysia

${ }^{c}$ Transfusion Medicine Unit, Department of Pathology, Hospital Serdang, Selangor, Malaysia

${ }^{d}$ Regenerative Medicine Cluster, Advanced Medical and Dental Institute, Universiti Sains Malaysia, Pulau Pinang, Malaysia

\begin{tabular}{|c|c|}
\hline & ABSTRACT \\
\hline & $\begin{array}{l}\text { INTRODUCTION: Transfusion of blood and blood components among obstetrics } \\
\text { patients is a common practice but they are not without risks. This study aims to determine } \\
\text { crossmatch to transfusion ratio (C:T ratio) and to assess the factors that influence red } \\
\text { blood cells (RBC) transfusion among obstetrics patients in a single tertiary hospital. } \\
\text { MATERIAL AND METHODS: This was a retrospective cohort study of RBC } \\
\text { crossmatch requests with data collected from } 350 \text { obstetrics patients. The patients were } \\
\text { grouped into either received or did not receive RBC transfusion. Demographics and } \\
\text { clinical characteristics were analysed using descriptive and multivariate analysis. } \\
\text { RESULTS: The mean C:T ratio was } 3.1 \text {. Of } 350 \text { patients, } 149(42.6 \% \text { patients received }\end{array}$ \\
\hline $\begin{array}{l}\text { Keywords } \\
\text { crossmatch, obstetrics, red blood cell, } \\
\text { transfusion }\end{array}$ & $\begin{array}{l}\text { RBC transfusion. Patients with i) underlying hemoglobinopathy }(75.9 \%) \text {, ii) history of } \\
\text { postpartum haemorrhage }(63.6 \%) \text {, iii) underwent instrumental assisted delivery }(64.3 \%) \text {, }\end{array}$ \\
\hline $\begin{array}{l}\text { Corresponding Author } \\
\text { Dr. Siti Salmah Noordin } \\
\text { Regenerative Medicine Cluster, Advanced } \\
\text { Medical and Dental Institute, } \\
\text { Universiti Sains Malaysia, } \\
\text { Bertam, } 13200 \text { Kepala Batas, } \\
\text { Pulau Pinang, Malaysia } \\
\text { Tel No: }+604-5622888 \text { (ext 2121) } \\
\text { Email: ssalmah@usm.my }\end{array}$ & $\begin{array}{l}\text { and iv) with haemoglobin levels of }<70 \mathrm{~g} / \mathrm{L} \text { upon crossmatch requests }(90.5 \%) \text {, did } \\
\text { receive } \mathrm{RBC} \text { transfusion. Significant factors associated with } \mathrm{RBC} \text { transfusion } \\
\text { were i) Caesarean section }(p=0.011) \text {, ii) haemoglobin level }<99 \mathrm{~g} / \mathrm{L}(p<0.001) \text {, iii) } \\
\text { estimated blood loss }>1000 \mathrm{~mL}(p<0.001) \text {, and iv) symptomatic anaemia }(p=0.029) \text {. } \\
\text { CONCLUSION: The mean C:T ratio in our study was high. Identifying the factors }\end{array}$ \\
\hline $\begin{array}{l}\text { Received: 15th September 2021; Accepted: } \\
\text { 1st December } 2021\end{array}$ & $\begin{array}{l}\text { contributing to RBC transfusion among obstetrics patients are important to reduce } \\
\text { unnecessary crossmatch and subsequently improve blood inventory management, and }\end{array}$ \\
\hline oi: https://doi.org/10.31436/imjm.v21i1 & thus further reduce the risks associated with allogeneic transfusion. \\
\hline
\end{tabular}

\section{INTRODUCTION}

Pregnancy is associated with anatomical and physiological changes to accommodate the foetus's development and preparation of the mother for delivery. Amongst these changes include haematological changes, which indirectly affect the blood transfusion practice in obstetrics patients. ${ }^{1}$ Over the years, blood transfusion rate in obstetrics, particularly among patients with postpartum haemorrhage $(\mathrm{PPH})$ had shown an increasing trend despite recent advancements in this field. ${ }^{2}$

Common causes of transfusion in obstetrics include anaemia in pregnancy, antenatal haemorrhage, and $\mathrm{PPH}$ with predominantly red blood cells (RBC) products being transfused. 3,4 Additionally, for patients who underwent
Caesarean section, risk factors such as placenta previa, abruptio placenta, and preoperative maternal anaemia had shown a significant association with blood transfusion. ${ }^{5}$ Furthermore, clinical factors such as age, preoperative haemoglobin $(\mathrm{Hb})$, and perioperative blood loss also played an important role in determining the transfusion requirement among obstetrics patients. ${ }^{6}$

Nevertheless, transfusion is not without adverse risks such as allergy reactions, febrile non-haemolytic transfusion reactions, haemolytic transfusion reactions, transfusion-transmitted infections, alloimmunization, transfusion-associated acute lung injury, and many more. ${ }^{7}$ Moreover, it is important to outweigh the benefits and 
risks before transfusion as inappropriate transfusion during pregnancy has additional adverse risks such as haemolytic disease of the foetus and newborn. ${ }^{8}$

Previous literature had shown an increasing demand but with underutilization of the requested blood in obstetrics. 9 The blood underutilization had led to increase blood wastage, reduce resources, and subsequently increased operational cost. Among the methods used to assess blood utilization's appropriateness is the crossmatch to transfusion ratio (C:T ratio) which is one of the quality indicators. ${ }^{10}$ This study aims to assess the $\mathrm{C}: \mathrm{T}$ ratio and to determine the factors contributing to RBC transfusion among obstetrics patients. By analysing these factors, it will help to improve the blood transfusion practice in obstetrics patients as well as the inventory management of the blood transfusion service.

\section{MATERIAL AND METHODS}

\section{Study design}

This was a retrospective cohort study involving data collection from the obstetrics patients at Hospital Serdang who required RBC crossmatch from 1st June 2016 until 31st December 2016. Hospital Serdang is one of the tertiary hospitals in Malaysia, which provides clinical service to nearly half a million population. The Obstetrics and Gynaecological Department has the largest number of patients compared to the other departments in this hospital.

\section{Sampling and data collection}

The sample size was calculated using Power and Sample Size Calculation Software to compare two independent proportions with an estimation of 0.07 for the proportion of patients transfused without risk factors (P0), 0.01 for the proportion of patients transfused with risk factors (P1), power of 0.8 , alpha of 0.05 , and $10 \%$ dropout. 11,12 The final calculated sample size was 350 . The sampling methods were performed through systematic random sampling for every second patient listed in the sequence of the date of crossmatch requests. The inclusion criteria included obstetrics patients who required crossmatch and patients with complete medical records. The exclusion criteria were patients with crossmatch blood requests in which their surgery schedule was cancelled or delayed from the scheduled date and the obstetrics patients that only request for group and typing of RBC.

Data were retrieved from the laboratory information system. The collected data include demographic and clinical characteristics of patients such as medical history, pregnancy history, types of admission (emergency or elective admissions from outpatients, and antenatal clinics), Hb level upon crossmatch requests and estimated blood loss (EBL). The EBL was determined at the discretion of the staff involved (usually by visual estimation, pads, and surgical clothes weight, and from the surgical container). Nil EBL denotes patients that had symptomatic anaemia without any bleeding.

\begin{tabular}{l} 
The C:T ratio was calculated for each month based on the formula: \\
$\begin{array}{l}\mathrm{C}: \mathrm{T} \\
\text { ratio }\end{array}=\frac{\text { number of units crossmatched }}{\text { number of units transfused }}$ \\
\hline
\end{tabular}

\section{Data analysis}

Statistical analysis was performed using Statistical Package for Social Sciences (SPSS) version 23.0 (SPSS, Chicago, Illinois, USA). Simple logistic regression was performed to analyse each variable's association as risk factors and transfusion. Those with a $p<0.25$ were considered for variable selection into the multiple logistic regression (MLogR) model. For variable selection in MLogR, the forward and backward methods were used to get the best model, which was the best fit, parsimonious, biologically plausible, and statistically significant. The $p$-value was set at 0.05 .

\section{Ethics}

Ethical approval was obtained from the Human Research Ethics Committee, Universiti Sains Malaysia (HREC, USM) USM/JEPeM/16120542, from the Ministry of Health with National Medical Research Register (NMRR) protocol number of NMRR-16-2133-32992, and Hospital Serdang. 


\section{RESULTS}

\section{C:T ratio}

A total of 889 crossmatch requests were received from the obstetrics patients from June 2016 until December 2016. Out of these requests, only 289 (33\%) were transfused. The C:T ratio for each month is shown in Figure 1 with the mean $\mathrm{C}: \mathrm{T}$ ratio of 3.1 .

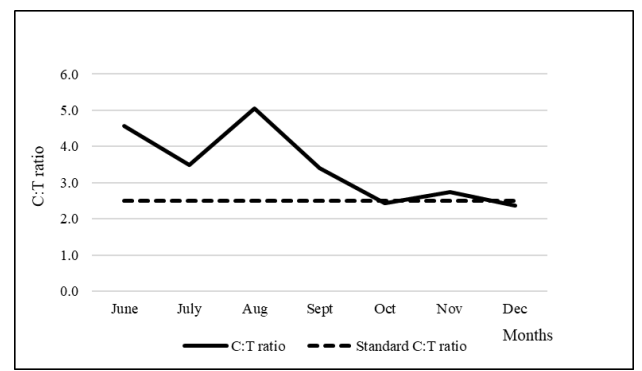

Figure 1: C:T ratio from June until December 2016. The standard C:T ratio is $2.5 .{ }^{14}$

\section{Characteristics of the Crossmatch Requests among Obstetrics Patients}

Demographics and clinical characteristics of crossmatch requests for 350 study patients are shown in Table I. From 350, 149 (42.6\%) obstetrics patients had received RBC transfusion, and 201 (57.4\%) patients did not receive RBC transfusion during the study period. All three patients who underwent laparotomy and all 13 patients with EBL > $2000 \mathrm{~mL}$ received RBC transfusion. Almost all nil-EBL patients who had symptomatic anaemia were transfused $(94.1 \%)$.

\section{Factors Sssociated with RBC Transfusion among Obstetrics Patients}

In the univariate analysis using simple logistic regression, laparotomy was combined with retained placenta due to few sample data in those variables (Table II). Among the significant risk factors, nil-EBL (symptomatic anaemia) showed the strongest association with RBC transfusion $(\mathrm{cOR}=61.714 ; 95 \% \mathrm{CI}=14.103-270.063 ; p<0.001)$.

For multivariable analysis, EBL $>2000 \mathrm{~mL}$ was grouped with EBL 1000-1999 mL as EBL>1000 mL during the analysis. The forward and backward methods were applied and gave the same decision for the best model. The significant variables for the final regression model of factors associated with RBC transfusion among obstetrics patients were tabulated in Table III. The patients that underwent Caesarean section had $62.3 \%$ less chance to receive blood transfusion compared to those with SVD $(\mathrm{aOR}=0.377,95 \% \mathrm{CI}=0.178-0.797 ; p=0.011)$. Additionally, those with $\mathrm{Hb}$ level of $<70 \mathrm{~g} / \mathrm{L}$ had $96.7 \%$ more chance to receive RBC transfusion compared to those with $\mathrm{Hb}$ level $>110 \mathrm{~g} / \mathrm{L} \quad(\mathrm{aOR}=96.72 ; 95 \%$ $\mathrm{CI}=15.792-592.308 ; p<0.001)$ and those with $\mathrm{EBL}>$ $1000 \mathrm{~mL}$ had $66.9 \%$ more chance to received $\mathrm{RBC}$ transfusion than those EBL $<500 \mathrm{~mL}(\mathrm{aOR}=66.89 ; 95 \%$ $\mathrm{CI}=23.109-193.584 ; \quad p<0.001)$. Similar with univariate analysis, nil EBL (symptomatic anemia) showed the strongest association with RBC transfusion among obstetrics patients $\quad(\mathrm{aOR}=209.60 ; \quad 95 \% \quad \mathrm{CI}=1.754$ 25053.68; $p=0.029$ ).

\section{DISCUSSION}

Blood transfusion plays an important role in the comprehensive care of the patient. Due to the scarcity of resources, economic constraints, and risk of adverse transfusion reactions, blood transfusion is usually administered if clinically indicated. Even though strategies to promote blood safety and appropriate clinical use of blood and blood products are advocated globally, overordering of blood is still a major issue in blood transfusion service even among obstetrics patients. ${ }^{13}$

The present study showed that the overall C:T ratio was 3.1, which was higher than the recommended C:T ratio of 2.5 set by Technical Specifications of Hospital Performance Indicators for Accountability from Ministry of Health Malaysia. ${ }^{14}$ Nevertheless, this finding was similar to a study by Murugesan and Subbiah, which reported the C:T ratio of $3.5 .{ }^{15}$ One of the reasons for the high C:T ratio was due to high crossmatch requests from patients who underwent Caesarean section and patients who were in labour. Nonetheless, the C:T ratio in our study showed improvement over time which was due to series of continuing medical education (CME) about safe transfusion practices to all the obstetrics healthcare providers in the hospital since August 2016. 
Table I: Characteristics of obstetrics patients that required crossmatch request, $(N=350)$

\begin{tabular}{|c|c|c|c|}
\hline \multirow[b]{2}{*}{ Variables } & \multicolumn{2}{|c|}{ Transfusion } & \multirow[b]{2}{*}{$\begin{array}{c}\text { Total crossmatch request } \\
\text { n (\%) }\end{array}$} \\
\hline & $\begin{array}{l}\text { Yes } \\
\text { n (\%) }\end{array}$ & $\begin{array}{c}\text { No } \\
\text { n (\%) }\end{array}$ & \\
\hline \multicolumn{4}{|l|}{ Age by category } \\
\hline$<19$ years old & $1(25.0)$ & $3(75.0)$ & $4(1.1)$ \\
\hline $20-34$ years old & $104(46.6)$ & $119(53.4)$ & $223(63.7)$ \\
\hline$>35$ years old & $44(35.8)$ & $79(64.2)$ & $123(35.1)$ \\
\hline \multicolumn{4}{|l|}{ Trimester } \\
\hline First trimester & $1(50.0)$ & $1(50.0)$ & $2(0.6)$ \\
\hline Second trimester & $10(66.7)$ & $5(33.3)$ & $15(4.3)$ \\
\hline Third trimester & $134(41.1)$ & $192(58.9)$ & $326(93.1)$ \\
\hline Post delivery & $4(57.1)$ & $3(42.9)$ & $7(2.0)$ \\
\hline \multicolumn{4}{|l|}{ Gravida } \\
\hline 1 & $41(46.1)$ & $48(53.9)$ & $89(25.4)$ \\
\hline $2-4$ & $78(41.1)$ & $112(58.9)$ & $190(54.3)$ \\
\hline$>5$ & $30(42.3)$ & $41(57.7)$ & $71(20.3)$ \\
\hline \multicolumn{4}{|l|}{ Parity } \\
\hline 0 & $45(45.9)$ & $53(54.1)$ & $98(28.0)$ \\
\hline 1 & $34(47.2)$ & $38(52.8)$ & $72(20.6)$ \\
\hline 2 & $35(38.9)$ & $55(61.1)$ & $90(25.7)$ \\
\hline 3 & $12(27.3)$ & $32(72.7)$ & 44 (12.6) \\
\hline 4 & $11(42.3)$ & $15(57.7)$ & $26(7.4)$ \\
\hline$>5$ & $12(60.0)$ & $8(40.0)$ & $20(5.7)$ \\
\hline \multicolumn{4}{|l|}{ Types of admission } \\
\hline Emergency & $94(44.5)$ & $117(55.5)$ & $211(60.3)$ \\
\hline Elective & $55(39.6)$ & $84(60.4)$ & $139(39.7)$ \\
\hline \multicolumn{4}{|l|}{ Haematological-related disorders } \\
\hline Nil & $123(39.2)$ & $191(60.8)$ & $314(89.7)$ \\
\hline Haemoglobinopathy & $22(75.9)$ & $7(24.1)$ & $29(8.3)$ \\
\hline Thrombocytopenia & $4(57.1)$ & $3(42.9)$ & $7(2.0)$ \\
\hline Bleeding disorders & 0 & 0 & 0 \\
\hline \multicolumn{4}{|l|}{ Pregnancy-related illness } \\
\hline Nil & $96(41.4)$ & $136(58.6)$ & $232(66.3)$ \\
\hline Placental abnormality & $28(45.9)$ & $33(54.1)$ & $61(17.4)$ \\
\hline Multiple pregnancy & $8(32.0)$ & $17(68.0)$ & $25(7.1)$ \\
\hline Pre-eclampsia & $10(47.6)$ & $11(52.4)$ & $21(6.0)$ \\
\hline History of PPH & $7(63.6)$ & $4(36.4)$ & $11(3.1)$ \\
\hline \multicolumn{4}{|l|}{ Caesarean history } \\
\hline 0 & $100(48.5)$ & $106(51.5)$ & $206(58.9)$ \\
\hline 1 & $29(44.6)$ & $36(55.4)$ & $65(18.6)$ \\
\hline$>2$ & $20(25.3)$ & $59(74.7)$ & $79(22.6)$ \\
\hline \multicolumn{4}{|l|}{ Procedures } \\
\hline Nil & $33(91.7)$ & $3(8.3)$ & $36(10.3)$ \\
\hline SVD & $42(48.8)$ & $44(51.2)$ & $86(24.6)$ \\
\hline Caesarean & $65(30.4)$ & $149(69.6)$ & $214(61.1)$ \\
\hline Instrumental assisted delivery & $9(64.3)$ & $5(35.7)$ & $14(4.0)$ \\
\hline \multicolumn{4}{|l|}{ Complications of delivery } \\
\hline Nil & $124(39.7)$ & $188(60.3)$ & $312(89.1)$ \\
\hline Vaginal tear & $16(64.0)$ & $9(36.0)$ & $25(7.1)$ \\
\hline Retained placenta & $6(60.0)$ & $4(40.0)$ & $10(2.9)$ \\
\hline Laparotomy & $3(100.0)$ & 0 & $3(0.9)$ \\
\hline \multicolumn{4}{|l|}{ Hb level upon crossmatch $(\mathrm{g} / \mathrm{L})$} \\
\hline$>110$ & $21(16.0)$ & $110(84.0)$ & $131(37.4)$ \\
\hline $100-109$ & $13(22.8)$ & $44(77.2)$ & $57(16.3)$ \\
\hline $70-99$ & $96(68.1)$ & $45(31.9)$ & $141(40.3)$ \\
\hline$<70$ & $19(90.5)$ & $2(9.5)$ & $21(6.0)$ \\
\hline \multicolumn{4}{|l|}{ Estimated blood loss (mL) } \\
\hline$<500$ & $35(20.6)$ & $135(79.4)$ & $170(48.6)$ \\
\hline $500-999$ & $28(37.3)$ & $47(62.7)$ & $75(21.4)$ \\
\hline $1000-1999$ & $41(70.7)$ & $17(29.3)$ & $58(16.6)$ \\
\hline$>2000$ & $13(100.0)$ & 0 & $13(3.7)$ \\
\hline Nil & $32(94.1)$ & $2(5.9)$ & $34(9.7)$ \\
\hline
\end{tabular}

Hb: haemoglobin; PPH: postpartum haemorrhage; SVD: spontaneous vaginal delivery 
Table II: Characteristics of obstetrics patients associated with RBC transfusion

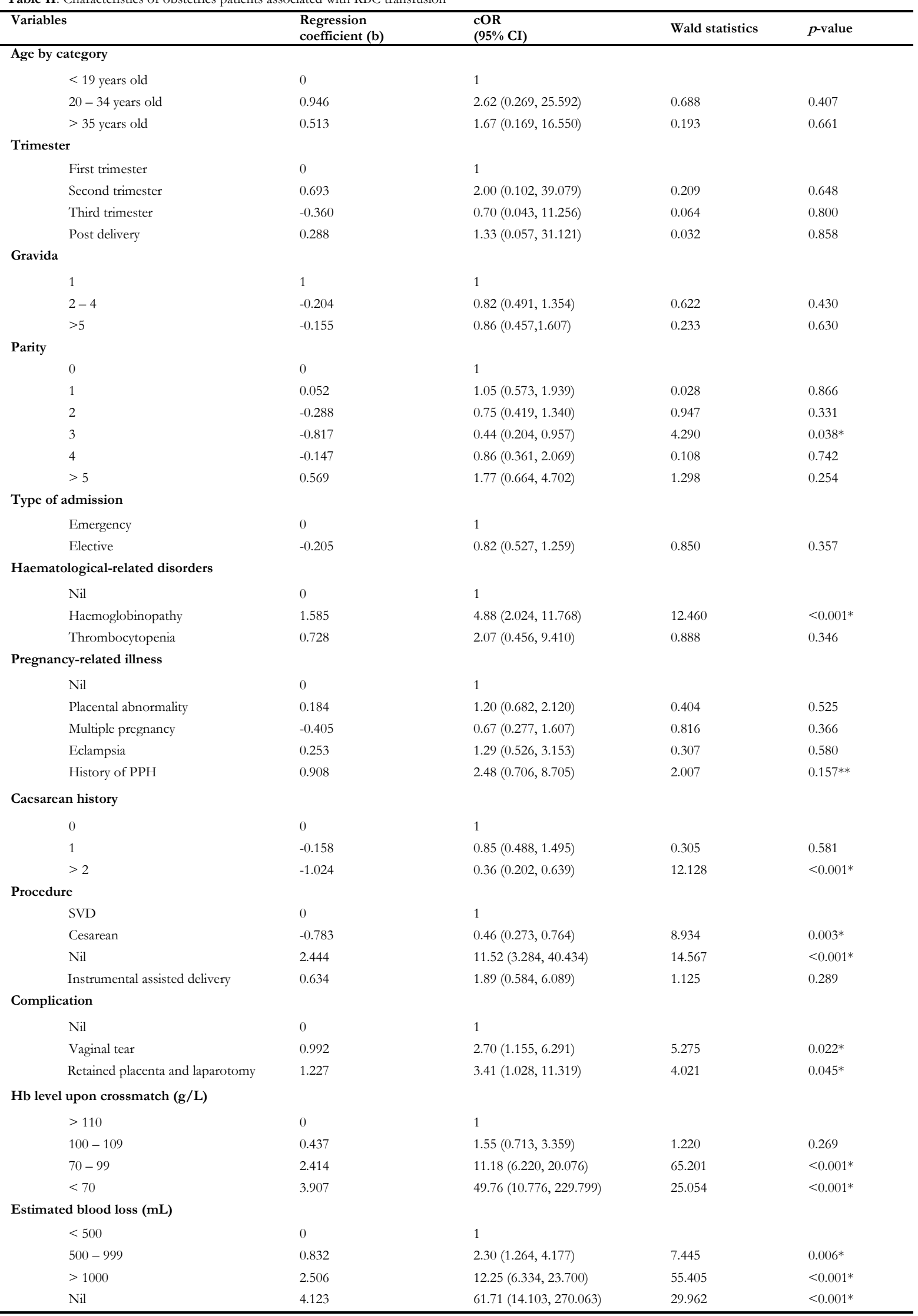

Hb: hemoglobin; PPH: postpartum hemorrhage; SVD: spontaneous vaginal delivery; cOR: crude odds ratio; CI: confidence intervals. *significant at $p<0.05$

$* * p<0.25$ 
Table III: Final regression model of factors associated with RBC transfusion among obstetrics patients

\begin{tabular}{|c|c|c|c|c|}
\hline Variables & $\begin{array}{l}\text { Regression } \\
\text { coefficient (b) }\end{array}$ & aOR $(95 \% \mathrm{CI})$ & $\begin{array}{l}\text { Wald } \\
\text { statistics }\end{array}$ & $p$-value \\
\hline \multicolumn{5}{|l|}{ Procedure } \\
\hline SVD & 0 & 1 & & \\
\hline Caesarean & -0.976 & $0.377(0.178,0.797)$ & 6.529 & $0.011 *$ \\
\hline Nil & -2.486 & $0.083(0.001,7.726)$ & 1.156 & 0.282 \\
\hline $\begin{array}{l}\text { Instrumental } \\
\text { assisted delivery }\end{array}$ & 0.893 & $2.441(0.413,14.448)$ & 0.968 & 0.325 \\
\hline \multicolumn{5}{|c|}{ Hb level upon crossmatch $(\mathrm{g} / \mathrm{L})$} \\
\hline$>110$ & 0 & 1 & & \\
\hline $100-109$ & 0.371 & $1.449(0.513,4.090)$ & 0.491 & 0.483 \\
\hline $70-99$ & 3.460 & $31.81(11.944,84.723)$ & 47.922 & $<0.001 *$ \\
\hline$<70$ & 4.572 & $96.72(15.792,592.308)$ & 24.447 & $<0.001 *$ \\
\hline \multicolumn{5}{|c|}{ Estimated blood loss (mL) } \\
\hline$<500$ & 0 & 1 & & \\
\hline $500-999$ & 1.140 & $3.13(1.395,7.014)$ & 7.657 & $0.006^{*}$ \\
\hline$>1000$ & 4.203 & $66.89(23.109,193.584)$ & 60.083 & $<0.001 *$ \\
\hline Nil & 5.345 & $209.60(1.754,25053.268)$ & 4.797 & $0.029 *$ \\
\hline
\end{tabular}

SVD: spontaneous vaginal delivery; Hb: hemoglobin; aOR: adjusted odds ratio; CI: confidence intervals.

*significant at $\mathrm{p}<0.05$

Multicollinearity test and the interaction term were checked and not found.

Hosmer - Lemeshow test $(p=0.931)$, classification table (overall correctly classified percentage $=84.3 \%$ ), and area under curve $(92.0 \%)$ )

were applied to check model fitness.

In our study, most of the patients that received transfusion were in their reproductive age of 20-34 years old and were multigravida. This finding represented the Malaysian population in 2016, which demonstrated that the total fertility rate among women aged 15-49 years old in 2016 was 1.9 babies with women aged 30-34 years old had recorded the highest fertility rate of 120 births per 1000 women. ${ }^{16}$

Globally, nearly 36.6\% of pregnant women had anaemia based on estimation by the World Health Organization in 2016 and it only decreased to $36.5 \%$ in $2019 .{ }^{17}$ Anaemia in pregnancy is associated with an increased risk of preterm birth and low birth weight baby, as well as maternal and perinatal mortality. ${ }^{18}$ During pregnancy, anaemia is defined as $\mathrm{Hb}$ level less than $110 \mathrm{~g} / \mathrm{L}$ in the second trimester, less than $105 \mathrm{~g} / \mathrm{L}$ in the third trimester, and $\mathrm{Hb}$ level less than $100 \mathrm{~g} / \mathrm{L}$ in the postpartum period. However, in the postnatal period with no ongoing or life-threatening bleeding, the transfusion decision should be made based on a case basis if the $\mathrm{Hb}$ level is less than $70 \mathrm{~g} / \mathrm{L} .19$ Our study noted that those patients who had $\mathrm{Hb}$ level $>70 \mathrm{~g} /$ $\mathrm{L}$ and received $\mathrm{RBC}$ transfusion were mostly because of their underlying symptomatic anaemia or had developed significant blood loss during delivery. Furthermore, we also found that symptomatic anaemia showed the strongest association with RBC transfusion. However, as most of the anaemia in pregnancy is due to iron deficiency, therefore adherence to nutrition, and oral iron or parenteral iron is the preferred treatment in such cases before RBC transfusion is considered. ${ }^{20}$

A previous study had demonstrated that hemoglobinopathy was among the common causes of anaemia in obstetrics patients, especially in areas where the thalassemia trait is prevalent. ${ }^{21}$ Malaysia had recorded about 7,605 cases of thalassemia in 2016; an estimated 150-300 babies were born yearly with severe thalassemia syndromes. ${ }^{22}$ For the obstetrics patient with hemoglobinopathy, maintaining the maternal $\mathrm{Hb}$ level of more than $100 \mathrm{~g} / \mathrm{L}$ is important to ensure adequate foetal growth and to prevent other pregnancy-associated complications such as thrombosis. ${ }^{23}$

In the patient with a history of PPH, our study had found that $63.6 \%$ of them received $\mathrm{RBC}$ transfusion. A previous study by Nyfløt et al. had shown that there were 9-fold odds of severe $\mathrm{PPH}$ in the next pregnancy, suggesting that both environmental factors such as maternal haemostasis changes well as genetic factors may 
predispose these patients to develop PPH. ${ }^{24}$ Additionally, $\mathrm{PPH}$ is also a common cause for blood transfusion among obstetrics patients with 14.5 per 100 births of $\mathrm{PPH}$ patients received RBC transfusion; higher risks among vaginal delivery. ${ }^{25}$

This present study also showed that obstetrics patients who underwent instrumental assisted delivery had 2.4 times higher risks of receiving blood transfusion than spontaneous vaginal delivery (SVD). Similar findings were also noted by Zdanowicz et al, which showed that RBC transfusion was more frequent in instrumental assisted delivery than Caesarean section or SVD. ${ }^{26}$ The requirement for $\mathrm{RBC}$ transfusion in instrumental assisted delivery may be attributed to complications of these procedures such as perineal or cervical tear. ${ }^{27}$

The obstetrics procedure with protective findings to the $\mathrm{RBC}$ transfusion in our study was Caesarean section; those who underwent this procedure had a $62.3 \%$ less chance to receive $\mathrm{RBC}$ transfusion than those who underwent normal SVD. A previous study by Kathpalia et al had reported that $2.8 \%$ of SVD patients received blood transfusion compared to $1.6 \%$ in elective Caesarean section and $3.8 \%$ in emergency Caesarean section. ${ }^{28}$ The possible explanation was because most of the Caesarean section was performed by a more senior doctor and most of it was an elective procedure in which the patient was initially screened for other pregnancy-related complications. Therefore, the RBC transfusion requirement was less in the patient who underwent Caesarean section as compared to SVD.

Our study was a retrospective study conducted in a single centre that might limit the generalizability. The number of subjects in our study was smaller than in other studies which consisted of up to thousands of subjects. However, the sample size of our study was calculated to achieve a significant result. In our study, there might be a possibility of homogenous sample population due to the shorter duration of data collection and small sample size. There was also a low incidence of some risk factors that were studied. However, the inclusion and exclusion criteria and systematic random sampling used in our study had reduced the possibility of selection biases.

\section{CONCLUSION}

Our study showed high C:T ratio which gradually decreased over time. Therefore, identifying the factors associated with RBC transfusion among obstetrics patients are important to prevent excessive crossmatching as it may lead to adverse consequences on blood transfusion services such as the reduction in blood availability in an emergency state. Thus, effective strategies to reduce unnecessary allogeneic blood transfusion such as CME about safe transfusion practice, periodical audits about the demand and utilization of RBC transfusion, and incorporation of patient blood management strategies such as the use of iron therapy in treating iron deficiency anaemia should also be implemented.

\section{CONFLICTS OF INTEREST}

The authors declare no conflicts of interest.

\section{ACKNOWLEDGEMENTS}

We would like to thank Universiti Sains Malaysia (USM) for providing the USM Research Short Term Grant (304.CIPPT.6315165). We would also like to thank the staff in Transfusion Medicine Unit, Hospital Serdang, and Dr. Wan Hamilton Wan Hassan from Obstetrics and Gynecology Department, Hospital Serdang for their help in conducting this study.

\section{REFERENCES}

1. Soma-Pillay P, Nelson-Piercy C, Tolppanen H, Mebazaa A. Physiological changes in pregnancy. Cardiovasc J Afr. 2016;27(2):89-94.

2. Thurn L, Wikman A, Westgren M, Lindqvist PG. Massive blood transfusion in relation to delivery: incidence, trends and risk factors: a population-based cohort study. BJOG. 2019;126(13):1577-86.

3. Chawla S, Bal MHK, Vardhan BS, Jose CT, Sahoo I. Blood Transfusion Practices in Obstetrics: Our Experience. J Obstet Gynaecol India. 2018;68(3):204207.

4. Akingbola TS, Bello OO. Obstetric emergencies and transfusion needs in a Nigerian hospital. Hematol 
Transfus Int J. 2016;2(6):107-10.

5. Akinlusi FM, Rabiu KA, Durojaiye IA, Adewunmi AA, Ottun TA, Oshodi YA. Caesarean deliveryrelated blood transfusion: correlates in a tertiary hospital in Southwest Nigeria. BMC Pregnancy Childbirth. 2018;18(1):24.

6. Murphy MF, Stanworth SJ, Yazer M. Transfusion practice and safety: current status and possibilities for improvement. Vox Sang. 2011;100(1):46-59.

7. Sahu S, Hemlata, Verma A. Adverse events related to blood transfusion. Indian J Anaesth. 2014;58(5):54351.

8. Dajak S, Culić S, Stefanović V, Lukačević J. Relationship between previous maternal transfusions and haemolytic disease of the foetus and newborn mediated by non- $\mathrm{RhD}$ antibodies. Blood Transfus. 2013;11(4):528-32.

9. Husain S, Imtiaz R, Husain S, Izhar R. Utilization of Blood and Appropriateness of Blood Transfusion in a Department of Obstetrics and Gynecology in Karachi. J South Asian Fed Obstet Gynaecol. 2019;11(6):345-8. 10. Anyaegbu CC. Quality indicators in Transfusion Medicine: the building blocks. ISBT Science Series. 2011;6(1):35-45.

11. Dupont WD, Plummer WD. Power and sample size calculations. A review and computer program. Control Clin Trials. 1990;11(2):116-28.

12. Patterson JA, Roberts CL, Bowen JR, et al. Blood transfusion during pregnancy, birth, and the postnatal period. Obstet Gynecol. 2014;123(1):126-33.

13. Yazdi AP, Alipour M, Jahanbakhsh SS, Gharavifard M, Gilani MT. A Survey of Blood Request Versus Blood Utilization at a University Hospital in Iran. Arch Bone Jt Surg. 2016;4(1):75-9.

14. Technical specifications of hospital performance indicators for accountability (HPIA) and specific indicators version 7.3. Ministry of Health Malaysia,2021.

15. Murugesan M, Subbiah S. Blood requisition and utilization practice in obstetric patients at tertiary care center from South India: A descriptive study. J Appl Hematol. 2018;9: 131-5.

16. Department of Statistics Malaysia. Vital Statistics, Malaysia, 2017 [online]. Available at URL: https:// www.dosm.gov.my/v1/index.php?r=column/
cthemeByCat\&cat $=165 \&$

bul_id=NXRCRDh0RENGeU13bC9EdzJ1cUFtZz0 9\&menu_id=L0pheU43NWJwRWVSZkIWdzQ4Tlh UUT09. Accessed June 18, 2021.

17. Global Health Observatory Data Repository.

Prevalence of anaemia in pregnant women -

Estimates by WHO region. World Health

Organization. 2017. [online]. Available at: https://

apps.who.int/gho/data/

view.main.ANAEMIAWOMENPWREG? lang=en.

Accessed June 20, 2021

18. Stephen G, Mgongo M, Hussein Hashim T, Katanga $\mathrm{J}$, Stray-Pedersen B, Msuya SE. Anaemia in Pregnancy: Prevalence, Risk Factors, and Adverse Perinatal Outcomes in Northern Tanzania. Anemia. 2018;2018:1846280.

19. Royal College of Obstetrics \& Gynaecologists. Blood Transfusion in Obstetrics. 2015 [online]. Available at: https://www.rcog.org.uk/globalassets/documents/ guidelines/gtg-47.pdf. Accessed June 20, 2021.

20. Zdanowicz JA, Surbek D. Patient blood management in obstetrics - Review. Transfus Apher Sci. 2019 Aug;58(4):412-415.

21. Susanti AI, Sahiratmadja E, Winarno G et al. Low Hemoglobin among Pregnant Women in Midwives Practice of Primary Health Care, Jatinangor, Indonesia: Iron Deficiency Anemia or $\beta$-Thalassemia Trait? Anemia. 2017;2017:6935648

22. Mohd Ibrahim, H. et al. Malaysian Thalassaemia Registry Report 2018. 1st ed. 2019. Medical Development Division, Ministry of Health, Malaysia [online]. Available at: https://www.moh.gov.my/ $\mathrm{moh} /$ penerbitan/Malaysian_Thalassaemia_ Registry_Report_2018.pdf. Accessed June 22, 2021.

23. Origa R, Comitini F. Pregnancy in Thalassemia. Mediterr J Hematol Infect Dis. 2019;11(1):e2019019.

24. Nyfløt LT, Sandven I, Stray-Pedersen B, et al. Risk factors for severe postpartum hemorrhage: a casecontrol study. BMC Pregnancy Childbirth. 2017;17 (1):17.

25. Ford JB, Patterson JA, Seeho SKM, Roberts CL. Trends and outcomes of postpartum haemorrhage, 2003-2011. BMC Pregnancy Childbirth. 2015;15:334.

26. Zdanowicz JA, Schneider S, Mueller M, Tschudi R, Surbek D. Red blood cell transfusion in obstetrics 
and its implication for patient blood management: a retrospective analysis in Switzerland from 1998 to 2016. Arch Gynecol Obstet. 2021;303(1):121-8.

27. Biru S, Addisu D, Kassa S, Animen S. Maternal complication related to instrumental delivery at Felege Hiwot Specialized Hospital, Northwest Ethiopia: A retrospective cross-sectional study. BMC Res Notes. 2019;12(1):482.

28. Kathpalia SK, Chawla J, Harith AK, Gupta P, Anveshi A. Blood transfusion practices among delivery cases: A retrospective study of two years. Med J Armed Forces India. 2016;72(Suppl 1):S43-5. 